\title{
Detection of the circulating antigen 14-3-3 protein of Schistosoma japonicum by time-resolved fluoroimmunoassay in rabbits
}

\author{
Chun-Yan Qian ${ }^{1}$, Biao Huang ${ }^{2 *}$, Chuan-Xin Yu ${ }^{{ }^{*}}$, Jue Zhang ${ }^{2}$, Xu-Ren Yin ${ }^{1}$, Jie Wang ${ }^{1}$, Li-Jun Song ${ }^{1}$, Wei Zhang \\ and Xue-Dan Ke ${ }^{1}$
}

\begin{abstract}
Background: Schistosomiasis remains a major public health concern that afflicts millions of people worldwide. Low levels of Schistosoma infection require more sensitive diagnostic methods. In this study, a time-resolved fluoroimmunoassay (TRFIA) was developed for detecting the signal transduction protein 14-3-3, a circulating antigen of Schistosoma japonicum.
\end{abstract}

Results: The detection limit of 14-3-3-TRFIA was $0.78 \mathrm{ng} / \mathrm{ml}$, with a linear measurement range from 0.78 to 800 $\mathrm{ng} / \mathrm{ml}$. The average intra-assay and inter-assay variability of this TRFIA was $8.9 \%$ and $12.2 \%$ respectively, and the mean recovery rate ranged from $92.1 \%$ to $115.5 \%$. Within the first 21 days post-infection in rabbits, the positive rates of the 14-3-3-TRFIA were distinctly higher compared to ELISA. All these findings illustrate that 14-3-3-TRFIA has a higher detection efficacy and is a good early diagnostic method for active Schistosoma infection.

Conclusions: A sandwich TRFIA for detecting the circulating antigen 14-3-3 of S. japonicum has been developed, and has demonstrated to be a good potential diagnostic method for schistosomiasis.

\section{Findings}

Over the past 50 years, the ongoing national control program has made great progress in controlling schistosomiasis japonica in China, but this disease is still a major public health concern that afflicts millions of people in endemic areas [1,2]. Definite diagnosis of the disease plays a key role in the control of schistosomiasis [3]. Detection of Schistosoma circulating antigen is an effective approach to discriminate between previous exposure and current infection [3]. Effective chemotherapy and other interventions, such as local environment alternation [4], livestock in pens, and health education, have dramatically reduced schistosome infections, and major infection in endemic areas remains on a low level [5-7]. If the level of circulating antigen in host serum is less than the detection limit of a diagnostic method, false-negative results will be obtained, which would result in some patients missing treatment. Selecting an

\footnotetext{
* Correspondence: huangbiao78@hotmail.com; chxnyu@163.com 'Jiangsu Institute of Parasitic Diseases, Wuxi, Jiangsu Province 214064, China ${ }^{2}$ Jiangsu Institute of Nuclear Medicine, Wuxi, Jiangsu Province 214063, China Full list of author information is available at the end of the article
}

abundant circulating antigen as target would be very helpful for developing a highly sensitive diagnostic method of schistosomiasis. The signal transduction protein 14-3-3 of S. japonicum is abundant in excretorysecretary extracts [8], soluble egg extracts [9] and adult worm extracts [10], and can be used for the diagnosis of acute and chronic S. japonicum infections [11]. In order to further improve the detection sensitivity of 14-3-3, a sandwich time-resolved fluoroimmunoassay (TRFIA) was developed using a pair of monoclonal antibodies, and it could be shown that TRFIA has a higher sensitivity in detecting 14-3-3 antigen of S. japonicum than an enzyme-linked immunosorbent assay (ELISA).

Diethylenetriaminepentaacetate (DTPA), bovine serum albumin (BSA), Tris and Triton X-100 were purchased from Sigma (St. Louis, MO, USA). A PD-10 column and a sepharose CL-6B column were obtained from the Pharmacia Company (Chalfont St Giles, UK). Pure water was produced by Barnstead Equipment (Dubuque, Iowa, USA). Flat-bottomed 96-well polystyrene microtiter plates were purchased from Nunc International (Roskilde, Denmark). Eu-labeling reagent 1244-302,

\section{C) Biomed Central}


including $\mathrm{N}^{\prime}$-[p-isothiocyanatobenzyl]-diethylenetriamine-N1, N2, N3, N4-tetraacetic acid, was obtained from Perkin-Elmer (Waltham, Massachusetts, USA). Beta-NTA was synthesized in our laboratory. AutoDELFIA $_{1235}$ (Perkin-Elmer, Waltham, Massachusetts, USA) was used to measure $\mathrm{Eu}^{3+}$ fluorescence in microtiter wells. An ELISA reader was purchased from Tecan Sunrise, Switzerland. All other reagents used were of analytical grade.

S. japonicum cercariae (Chinese strain), freshly released from infected intermediate host snails (Oncomelania hupensis), were provided by the Department of Snail Biology, Jiangsu Institute of Parasitic Diseases, China.

Twelve young Japanese rabbits, each weighing about $2.5 \mathrm{~kg}$, were purchased from the Experimental Animal Facility of Nanjing General Hospital of Nanjing Military Command, China, and raised in the Department of Animal Experiment, Jiangsu Institute of Parasitic Diseases. All rabbits were randomly divided into Group A and Group B. Group A included 10 rabbits, each infected with 500 cercariae of $S$. japonicum by abdominal skin without any treatment. Group B included two rabbits, and was used as negative control without any infection or treatment. Serum samples were collected at 0, 7, 14, 21, 28 days post-infection from all rabbits and stored at $-80^{\circ} \mathrm{C}$ for subsequent experiments. All rabbits were sacrificed at 42 days post-infection. Their worm burden and egg burden were measured. All experiments conformed to local government regulations and Chinese national laws on animal ethics.

Two monoclonal antibodies (McAbs), 5C6 and 5D1, against recombinant signal transduction protein 14-3-3 of $S$. japonicum were prepared as described previously $[12,13]$.

McAb 5C6 was labeled according to previously published methods $[14,15]$. The recombinant plasmid expressing the fusion protein of glutathione-S-transferase and signal transduction protein 14-3-3 was constructed and purified [16]. The 14-3-3 calibrators were prepared by serially diluting purified $14-3-3$ protein in assay buffer, ranging from $0-800 \mathrm{ng} / \mathrm{ml}[50 \mathrm{mmol} / \mathrm{l}$ Tris- $\mathrm{HCl}$ (pH 7.8), $0.9 \% \mathrm{NaCl}, 0.2 \% \mathrm{BSA}, 0.05 \% \mathrm{NaN}_{3}$, $20 \mu \mathrm{mol} / \mathrm{l}$ DTPA, and 0.1\% Tween-20].

After optimizing the test conditions, the following TRFIA procedure was adopted: McAb 5D1 was dissolved in coating buffer $(0.05 \mathrm{M}$ sodium bicarbonate buffer, $\mathrm{pH}$ 9.6) at a concentration of $10 \mu \mathrm{g} / \mathrm{ml}$. One hundred $\mu \mathrm{l}$ of this solution was added to each well and the plate was incubated overnight at $4^{\circ} \mathrm{C}$. After removing the antibody solution, the plate was blocked with 20 $\mathrm{g} / \mathrm{l} \mathrm{BSA}(200 \mu \mathrm{l} /$ well) in assay buffer for $2 \mathrm{~h}$ at room temperature. After the blocking solution was removed, the plates were dried in a high vacuum, and then stored at $-20^{\circ} \mathrm{C}$ in a sealed plastic bag with desiccant.
The procedure for 14-3-3-TRFIA was performed by using a two-step and non-competitive "sandwich-type" protocol. Briefly, $100 \mu \mathrm{l}$ of calibrators or serum samples without dilution were added into the coated wells, and then the plate was incubated with continuous shaking at $37^{\circ} \mathrm{C}$ for $2 \mathrm{~h}$. After four washes in washing solution [50 $\mathrm{mmol} / \mathrm{l}$ Tris- $\mathrm{HCl}$ buffer ( $\mathrm{pH} 7.8$ ), containing $0.9 \% \mathrm{NaCl}$, $0.2 \%$ Tween-20, and $0.05 \% \mathrm{NaN}_{3}$ ], $100 \mu \mathrm{l}$ of $\mathrm{Eu}^{3+}-5 \mathrm{C} 6$ conjugate diluted in assay buffer was added into each well. The plate was incubated at $37^{\circ} \mathrm{C}$ for $2 \mathrm{~h}$. After six washes, $200 \mu \mathrm{l}$ of enhancement solution was added into each well. The plate was shaken for $5 \mathrm{~min}$ before fluorescence reading. All analysis was performed by AutoDELFIA $_{1235}$ software. Duplicates of each sample were run. The calibration curve was plotted and concentrations in unknown samples were measured using the Multicalc software program, employing a spine algorithm on logarithmically transformed data. The antigen levels in sera were expressed as response counts. Response counts of samples above 2.1 times of the negative controls were judged as positive.

After optimizing the assay conditions, the following ELISA procedure was adopted: McAb 5D1 was dissolved in coating buffer at a concentration of $5 \mu \mathrm{g} / \mathrm{ml}$. One hundred $\mu$ of this solution was added to each well and the plate was incubated overnight at $4^{\circ} \mathrm{C}$. After removing the antigen solution, the plate was blocked by adding $200 \mu \mathrm{l} /$ well blocking solution [5\% skimmed milk power in $0.02 \mathrm{M}$ phosphate buffered saline with $0.05 \%$ Tween-20 (PBST), $\mathrm{pH} 7.2$ ] at $37^{\circ} \mathrm{C}$ for $1 \mathrm{~h}$. After the wells were emptied, $100 \mu \mathrm{l}$ of serum sample without dilution or calibrator was added to per well and incubated at $37^{\circ} \mathrm{C}$ for $1 \mathrm{~h}$. After four washes, $100 \mu \mathrm{l}$ of horseradish peroxidase (HRP)-conjugated $5 \mathrm{C} 6$ solution diluted in PBST was added and incubated at $37^{\circ} \mathrm{C}$ for $1 \mathrm{~h}$. The plate was washed as above and the reaction was visualized by adding $100 \mu \mathrm{l}$ of TMB substrate solution (GenScript, China) to each well for 5 - $10 \mathrm{~min}$ in dark at room temperature. The reaction was stopped by adding $100 \mu \mathrm{l} /$ well of stop solution $\left(1 \mathrm{M} \mathrm{H}_{2} \mathrm{SO}_{4}\right)$ and the absorbance of each well was measured at $450 \mathrm{~nm}$, using an ELISA plate reader. Duplicates of each sample were run. The antigen levels in sera were expressed as $A_{450}$ values. $A_{450}$ values of samples that were above 2.1 times of the negative controls were considered as positive [17].

Regression analysis was used to display the linearity and correlations. Analysis of data was performed using SPSS 13.0 (Chicago, IL, USA).

The detection limit of TRFIA was defined by the fluorescence of the zero calibrator plus two SD, which was repeated 10 times in one experiment. According to the fluorescence count of the 14-3-3 zero calibrator in the TRFIA method, the detection limit of 14-3-3-TRFIA was $0.78 \mathrm{ng} / \mathrm{ml}$. The calibration curve was linear from 
$0.78-800\left(0.78 \times 2^{0}-0.78 \times 2^{10}\right) \mathrm{ng} / \mathrm{ml}$ (Figure 1). The equation was:

$$
\mathrm{y}=14604.2380 \times \mathrm{x}^{0.8876}, \mathrm{R}^{2}=0.9984
$$

for the calibration curve of this TRFIA, where $y$ indicates values of the response counts (cps); $x$ indicates concentration of calibrator $(\mathrm{ng} / \mathrm{ml})$.

The detection limit of 14-3-3-ELISA was $6.25 \mathrm{ng} / \mathrm{ml}$, and its linear measurement range was from 6.25 to 200 $\left(0.78 \times 2^{3}-0.78 \times 2^{8}\right) \mathrm{ng} / \mathrm{ml}$ (Figure 1$)$. The equation was:

$$
y=0.6574 \times \log _{10} x-0.2724, R^{2}=0.9947
$$

for the calibration curve of 14-3-3-ELISA, where $y$ indicates $A_{450}$ values of the calibrators; x indicates concentration of calibrator $(\mathrm{ng} / \mathrm{ml})$ (The original data can be found in Additional file 1).

The calibration curve of 14-3-3-TRFIA showed a linear relationship over the concentration from $0.78-800$ $\mathrm{ng} / \mathrm{ml}$. For 14-3-3-ELISA, the calibration curve was linear from 6.25-200 $\mathrm{ng} / \mathrm{ml}$ before plateauing. All these data indicated that TRFIA has a better sensitivity and measurement range than ELISA.

The recovery rate was evaluated by comparing the measured and theoretical values. The recovery rates of 14-3-3-TRFIA and 14-3-3-ELISA were analyzed by adding recombinant 14-3-3 proteins at two different concentrations (20 and $100 \mathrm{ng} / \mathrm{ml}$ ) to healthy rabbit serum from Group B. The mean recovery rate of TRFIA ranged from $92.1 \%$ to $115.5 \%$, and the mean recovery rate of ELISA ranged from $94.1 \%$ to $105.5 \%$.

The average intra- and inter- assay variations were calculated for the precision of the assays. Intra-assay variations of the two assays were determined by

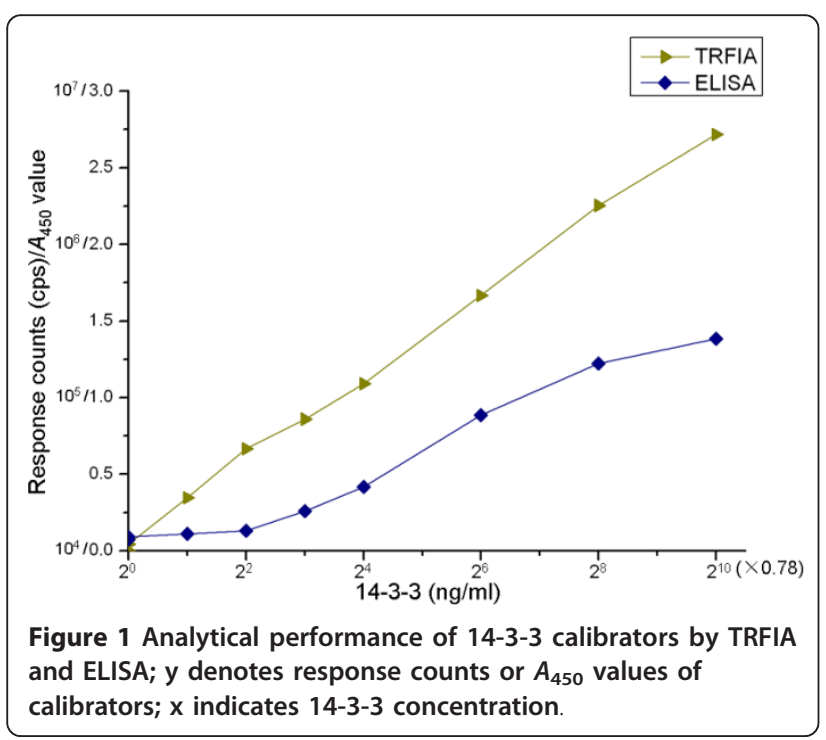

measuring the same two calibrators (20 and $100 \mathrm{ng} / \mathrm{ml}$ ) for 10 times repeatedly in one experiment. The variation was checked by calculating the

$$
\% \text { RSD }(\text { Relative Standard Deviation })=(S D / \text { mean }) \times 100 \text {, }
$$

and the applied acceptance criteria for immunoassays are $\%$ RSD $<20$ [18]. The average intra-assay variations of TRFIA and ELISA were $8.9 \%$ and 5.9\%, respectively. Interassay variations of the two assays were determined by measuring the same two calibrators (20 and $100 \mathrm{ng} / \mathrm{ml}$ ) on five independent days. The average inter-assay variation of TRFIA and ELISA were $12.2 \%$ and $7.4 \%$, respectively.

The $\mathrm{Eu}^{3+}$-labeled McAb 5C6 and the HRP labeled McAb 5C6 were stable for at least half a year at $-20^{\circ} \mathrm{C}$, and the results of the two methods with same reagents were reproducible over the same period.

Circulating antigen 14-3-3 protein in sera of rabbits collected at $0,7,14,21,28$ days post-infection was measured by TRFIA and ELISA simultaneously, the positive percentages of TRFIA were $0,30,70,100$ and 100, respectively, and the positive percentages of ELISA were $0,10,30,60$ and 100 (Figure 2). The positive rate of TRFIA was significantly higher than that of ELISA within 21 days post-infection, but both assays reached $100 \%$ at 28 days post-infection (The original data can be found in Additional file 2 and 3).

There was a strong positive relationship between the worm burden, egg burden and the levels of 14-3-3 protein within individual rabbits (The original data can be found in Additional file 4), and it could be also found that levels of 14-3-3 protein in rabbits infected with 1500 cercariae of $S$. japonicum were higher than in those infected with 500 cercariae of S. japonicum. (The original data are not shown).

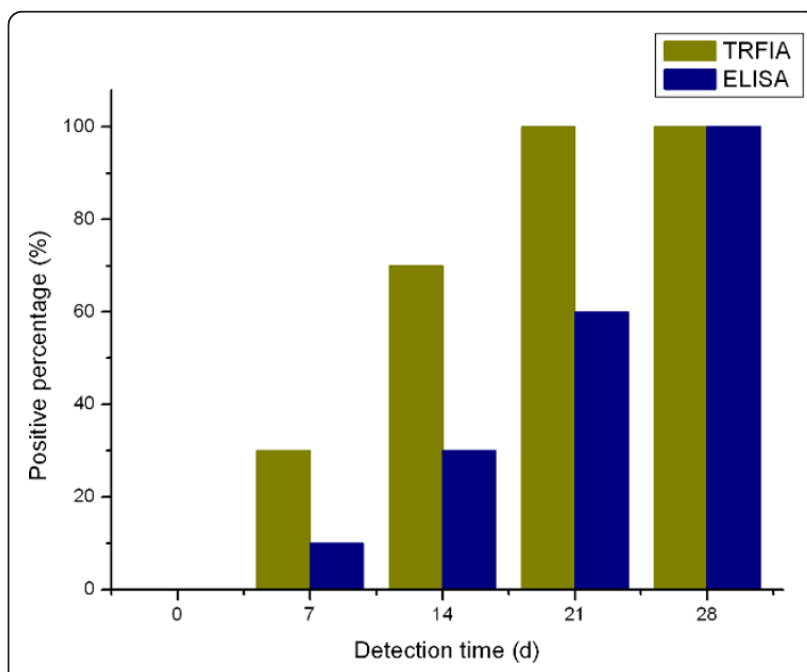

Figure 2 Comparison of positive percentage of circulating antigen 14-3-3 detected by TRFIA and ELISA. 
These results proved that the detection limit and the sensitivity of TRFIA are higher than those of ELISA, and TRFIA has stronger early diagnostic potential for schistosome infection. At present, the majority of schistosomiasis patients in epidemic areas of China have low infection levels. Circulating antigen levels are probably much lower than the detection limit of ELISA, indicating the need to develop more sensitive detection methods of schistosome circulating antigens [19].

TRFIA is based on the use of lanthanide chelate labels with unique fluorescence properties. Lanthanide chelate shows narrow and strong emission bands around 600 $\mathrm{nm}$ and an exceptionally long decay time, which allows the elimination of the high background of the fluorescent labels and increases the sensitivity and specificity of detection methods [20]. The sensitivity is further increased due to the dissociation-enhancement principle [21]. $\mathrm{Eu}^{3+}$-chelate is the most commonly used label in time resolved fluorometry-based analysis because of its higher fluorescence yield and lower background than other lanthanide complexes [14]. Therefore, TRFIA has the advantages of excellent sensitivity, wide measurement range and no radioactivity. A pair of monoclonal antibodies against signal transduction protein 14-3-3 of S. japonicum with highly specificity and affinity [12] was chosen to develop a sandwich TRFIA for detecting 143-3 protein. This assay combines characteristics of immunological methods and the sensitivity of a timeresolved fluorescence revelation system.

In this experiment, circulating antigen 14-3-3 protein in sera of rabbits collected post-infection was measured by TRFIA, and positive percentages of TRFIA could reach $100 \%$ after 21 days. Thus, for early diagnosis of Schistosoma infection, this TRFIA, combined with other detection methods $[22,23]$, could obtain more satisfying results. The value of this TRFIA for clinical diagnosis of schistosomiasis japonica should also be further assessed.

\section{Additional material}

Additional file 1: The original data of analytical performance of 143-3 calibrators by TRFIA and ELISA.

Additional file 2: The original data of the detection results of 14-3-3 in sera of Group A and B measured by TRFIA.

Additional file 3: The original data of the detection results of 14-3-3 in sera of Group A and B measured by ELISA.

Additional file 4: Worm burden, egg burden and the levels of 14-33 protein within individual rabbits at $\mathbf{4 2}$ days post-infection.

\section{Acknowledgements}

This work is supported by the National S \& T Major Program (Grant No. 2008ZX10004-011), the Preventive Medicine Project of Jiangsu Provincial Bureau of Health (Grant No. YZ201030), the Natural Science Foundation of China (Grant No. 30972581), the Special Fund for Public Interest of Science and Technology Department of Jiangsu Province (Grant No. BM2007704), the Natural Science Foundation of Jiangsu Province (Grant No. BK2008110) and Key Medical Personnel Foundation of Jiangsu Province (Grant No. RC2007095).

\section{Author details}

${ }^{1}$ Jiangsu Institute of Parasitic Diseases, Wuxi, Jiangsu Province 214064, China. ${ }^{2}$ Jiangsu Institute of Nuclear Medicine, Wuxi, Jiangsu Province 214063, China.

\section{Authors' contributions}

$\mathrm{BH}$ and $\mathrm{CXY}$ designed the study and interpreted the data; XRY, LUS, WZ and XDK collected the samples; JZ and JW did data analysis; CYQ performed the majority of experiments and prepared the manuscript. $\mathrm{BH}$ and $\mathrm{CXY}$ revised and finalized the manuscript. All authors read and approved the final manuscript.

\section{Competing interests}

The authors declare that they have no competing interests.

Received: 18 March 2011 Accepted: 28 May 2011

Published: 28 May 2011

\section{References}

1. Zhou XN, Guo JG, Wu XH, Jiang QW, Zheng J, Dang H, Wang XH, Xu J, Zhu HQ, Wu GL, Li YS, Xu XJ, Chen HG, Wang TP, Zhu YC, Qiu DC, Dong $X Q$, Zhao GM, Zhang SJ, Zhao NQ, Xia G, Wang LY, Zhang SQ, Lin DD, Chen MG, Hao Y: Epidemiology of schistosomiasis in the People's Republic of China, 2004. Emerg Infect Dis 2007, 13:1470-1476.

2. Li SZ, Luz A, Wang XH, Xu LL, Wang Q, Qian YJ, Wu XH, Guo JG, Xia G, Wang $L Y$, Zhou XN: Schistosomiasis in China: acute infections during 2005-2008. Chin Med J (Engl) 2009, 122:1009-1014.

3. Zhu YC: Immunodiagnosis and its role in schistosomiasis control in China: a review. Acta Trop 2005, 96:130-136.

4. Yang GJ, Vounatsou P, Zhou XN, Tanner M, Utzinger J: A potential impact of climate change and water resource development on the transmission of Schistosoma japonicum in China. Parassitologia 2005, 47:127-134.

5. Utzinger J, Booth M, N'Goran EK, Müller I, Tanner M, Lengeler C: Relative contribution of day-to-day and intra-specimen variation in faecal egg counts of Schistosoma mansoni within and after treatment with praziquantel. Parasitology 2001, 122:537-544.

6. Gryseels B, Polman K, Clerinx J, Kestens L: Human schistosomiasis. Lancet 2006, 368:1106-1118.

7. Zhu R, Gray DJ, Thrift AP, Williams GM, Zhang Y, Qiu DC, Zheng F, Li YS, Guo J, Zhu HQ, Wu WP, Li RS, McManus DP: A 5-year longitudinal study of schistosomiasis transmission in Shian village, the Anning River Valley, Sichuan Province, the Peoples' Republic of China. Parasit Vectors 2011, 4:43.

8. Liu F, Cui SJ, Hu W, Feng Z, Wang ZQ, Han ZG: Excretory/secretory proteome of the adult developmental stage of human blood fluke, Schistosoma japonicum. Mol Cell Proteomics 2009, 8:1236-1251.

9. $\quad$ Yang LL, Lv ZY, Hu SM, He SJ, Li ZY, Zhang SM, Zheng HQ, Li MT, Yu XB, Fung MC, Wu ZD: Schistosoma japonicum: proteomics analysis of differentially expressed proteins from ultraviolet-attenuated cercariae compared to normal cercariae. Parasitol Res 2009, 105:237-248.

10. Yu CX, Zhao F, Yin XR, Xiao D, Zhang JZ, Hua WQ, Qian CY, Song LJ, Wang J: Proteomics analysis of vomit and excretory/secretory products of Schistosoma japonicum. Chin J Schisto Control 2010, 22:304-309, (in Chinese).

11. Luo QL, Qiao ZP, Zhou YD, Li XY, Zhong ZR, Yu YJ, Zhang SH, Liu M, Zheng MJ, Bian MH, Shen JL: Application of signaling protein 14-3-3 and $26 \mathrm{kDa}$ glutathione-S-transferase to serological diagnosis of Schistosomiasis japonica. Acta Trop 2009, 112:91-96.

12. Qian $C Y$, Song $L$, Hua WQ, Yin XR, Wang J, Zhang W, Xu YL, Yu CX: Kinetics of circulating antigen 14-3-3 in sera of rabbits firstly infected with Schistosoma japonicum and treated with/without praziquantel. Parasitol Res 2011, 108:493-495.

13. Qian CY, Yu CX, Song $\sqcup$, Yin XR, Wang J, Xu YL, Zhang W: Characterization and preliminary application of six monoclonal antibodies against recombinant signal protein 14-3-3 of Schistosoma japonicum. Chin J Schisto Control 2011, 23:65-70, (in Chinese). 
14. Zhang J, Guo JZ, Xiao HL, Zhu L, Liu HY, Zhang Y, Huang B: Simultaneous detection of different serum pepsinogens and its primary application. World J Gastroenterol 2010, 16:3072-3077.

15. Andoh T, Nagasawa H: Development of a time-resolved fluoroimmunoassay for insulins and its application to monitoring of insulin secretion induced by feeding in the barfin flounder, Verasper moseri. Gen Comp Endocrinol 2002, 125:365-374.

16. Yin XR, Yu CX, Qian CY, Wang J, Song $\sqcup, X u$ YL, Zhang W: Expression and Characteristics of Schistosoma japonicum signaling protein 14-3-3. Chin J Schisto Control 2011, 23:168-172, (in Chinese).

17. Zhu C, Tian H, Lu L, Li Y, Feng Z, Ma L, Guan X: A study on producing monoclonal antibody with one diagnostic marker screened electrophoretically from the urine of individuals infected with Schistosoma japonicum. Diagn Microbiol Infect Dis 2000, 38:237-241.

18. Findlay JW, Smith WC, Lee JW, Nordblom GD, Das I, DeSilva BS, Khan MN, Bowsher RR: Validation of immunoassays for bioanalysis: a pharmaceutical industry perspective. J Pharm Biomed Anal 2000, 21:1249-1273.

19. Guan X, Shi Y: Collaborative study on evaluation of immunodiagnostic assays in schistosomiasis japonica by treatment efficacy assessment. Collaboration Group. Chin Med J (Engl) 1996, 109:659-664.

20. Bacigalupo MA, Meroni G, Secundo F, Lelli R: Time-resolved fluoroimmunoassay for quantitative determination of ampicillin in cow milk samples with different fat contents. Talanta 2008, 77:126-30.

21. Huang B, Xiao H, Zhang X, Zhu L, Liu H, Jin J: Ultrasensitive detection of pepsinogen I and pepsinogen II by a time-resolved fluoroimmunoassay and its preliminary clinical applications. Anal Chim Acta 2006, 571:74-78.

22. Xu J, Feng T, Lin DD, Wang QZ, Tang L, Wu XH, Guo JG, Peeling RW, Zhou XN: Performance of a dipstick dye immunoassay for rapid screening of Schistosoma japonicum infection in areas of low endemicity. Parasit Vectors 2011, 4:87.

23. Lei JH, Liu WQ, Sun CS, Tang CL, Li MJ, Chen YL, Li YL: Detection of circulating antigen in serum of mice infected with Schistosoma japonicum by immunomagnetic bead ELISA based on IgY. Acta Trop 2009, 111:39-43.

doi:10.1186/1756-3305-4-95

Cite this article as: Qian et al:: Detection of the circulating antigen 14-33 protein of Schistosoma japonicum by time-resolved

fluoroimmunoassay in rabbits. Parasites \& Vectors 2011 4:95.

\section{Submit your next manuscript to BioMed Central and take full advantage of:}

- Convenient online submission

- Thorough peer review

- No space constraints or color figure charges

- Immediate publication on acceptance

- Inclusion in PubMed, CAS, Scopus and Google Scholar

- Research which is freely available for redistribution

Submit your manuscript at www.biomedcentral.com/submit 